\section{Keine schlechtere Prognose nach Transplantation von HCV-positiver Spenderleber}

Aufgrund der Organknappheit werden HCV-infizierten Patienten mit dekompensierter Leberzirrhose zunehmend Leberorgane von HCV-positiven Spendern transplantiert. Die HCV-Positivität des Spenderorgans hat jedoch für die Prognose des Patienten keine negativen Folgen, berichten Forscher aus den USA.

Sie hatten das Schicksal von 33.668 HCV-positiven Patienten nach Lebertransplantation verfolgt, darunter 1.930 Fälle einer Leberübertragung eines HCV-positiven Spenders. Bezüglich Mortalität oder Spenderorgan-Versagen zeigten sich langfristig keine Unterschiede zwischen HCV-positiven und HCV-negativen Spenderorganen.

- DE

\section{Risiko-Gene für Alkohol- Hepatitis identifiziert}

Forscher aus England haben Risikogene identifiziert, die erklären, warum die Leber mancher Alkoholiker deutlich früher versagt als jene anderer Trinkgenossen. Wer die Risikogene PNPLA3 oder SLC38A4 trägt, hat ein deutlich höheres Risiko für eine schwere Alkoholhepatitis, die mit einer beträchtlichen Mortalität einhergeht.

Es wird geschätzt, dass weltweit jährlich eine halbe Million Menschen aufgrund einer Alkohol-bedingten Leberzirrhose sterben, 170.000 davon in Europa. Die WHO hat unseren Kontinent als die Region der Welt identifiziert, in der am meisten Alkohol pro Kopf konsumiert wird.

- DE

- EASL, Barcelona, 13.-17. April 2016

\section{Studie aus Hannover}

\section{Hepatitis B: Unter Migranten selten}

Die Hepatitis-B-Prävalenz ist unter Flüchtlingen mit 2,3\% leicht höher als bei gebürtigen Deutschen, aber nicht höher als bei bereits in Deutschland lebenden Personen mit Migrationshintergrund. Dies folgt aus einer Studie der Medizinischen Hochschule Hannover, bei der knapp 800 Flüchtlinge in Aufnahmelagern getestet wurden.

Die Studie zeigte auch, dass nur $18 \%$ der Flüchtlinge gegen Hepatitis B geimpft waren und nur 38\% eine HBV-Immunität aufwiesen.

$-\mathrm{DE}$

- EASL 2016, Barcelona, 13.-17.4.2016

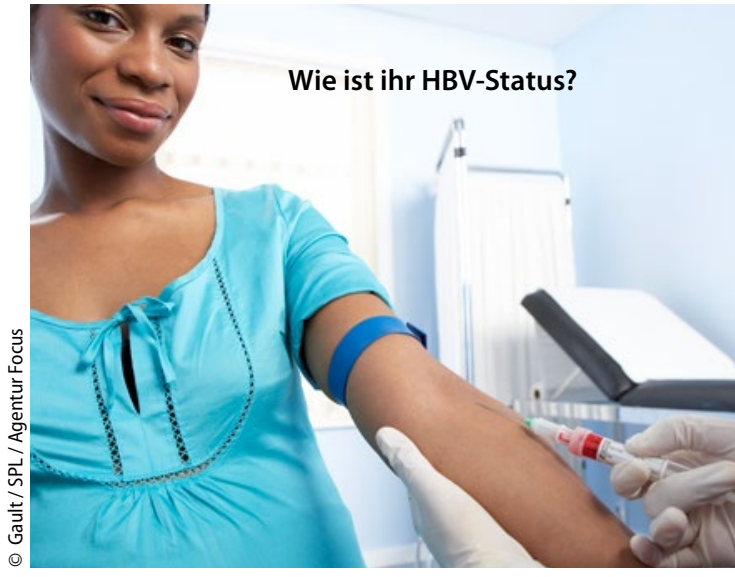

\title{
Virus-Elimination
}

\section{Hepatitis-C-Therapie wird immer kürzer}

_- Wenn man eine Hepatitis C im akuten Stadium erwischt, scheint eine auf sechs Wochen verkürzte antivirale Therapie auszureichen, um mit hoher Wahrscheinlichkeit eine Heilung zu erreichen. Dies berichten Hepatologen der Medizinischen Hochschule aus Hannover.

In einer Pilotstudie hatten sie 20 Patienten mit akuter HCV 6 Wochen lang mit Sofosbuvir/Ledipasvir behandelt und in allen Fällen 12 Wochen nach Therapieende das Virus eliminiert (SVR 100\%).

Forscher des Buda Hepatology Centre in Budapest berichteten Erfolge mit einer nur 4-wöchigen Kurzzeit-Therapie bei chronischer Hepatitis C. Sie hatte dabei RG-101 eingesetzt, ein Medikament, das an der microRNA-122 ansetzt, die das Virus zur Replikation benötigt.

In einer Phase-2-Studie mit 79 therapienaiven Patienten wurde es zweimal im Abstand von 4 Wochen injiziert. Gleichzeitig wurde 4 Wochen lang eines der neuen oralen Therapieregime appliziert. Interimsdaten zeigen, dass 37 von 38 Patienten 8 Wochen nach dieser Therapie Hepatitis-C-frei waren. - DE - EASL 2016, Barcelona, 13.-17.4.2016

\section{Simultane Immunantwort}

\section{Kombinierte Impfung gegen HCV und HIV in Entwicklung}

_ Forschern aus Oxford ist es erstmals gelungen, mit einem kombinierten Impfstoff gegen HIV und Hepatitis C eine simultane Immunantwort gegen beide $\mathrm{Vi}$ rusinfektionen bei Gesunden zu erzeugen.

Man schätzt, dass weltweit 2,3 Millionen Menschen mit HIV und HCV infiziert sind. Hepatitis-C-Komplikationen sind bei diesen Patienten die häufigste nicht durch AIDS bedingte Todesursache.
Zwar lässt sich Hepatitis C heute heilen und die HIV-Infektion langfristig beherrschen. Doch stehen die Medikamente vielen Patienten nicht zur Verfügung. Und sie verhindern nicht die Re-Infektion.

Deshalb wäre eine Impfung elegant. In der berichteten Phase-1-Studie wurden 32 gesunden Probanden nicht-replikative adenovirale Vektoren mit Fragmenten von HCV und HIV im Gepäck verabreicht. Später erfolgten BoosterImpfungen mit den gleichen VirusFragmenten mittels MVA-Vektoren.

Die Impfungen führten zu einer spezifischen T-Zell-Antwort, die bei den Auffrisch-Impfungen verstärkt wurden. Die Studie zeigte erstmals, dass eine gemeinsame Impfung machbar, effektiv und gut verträglich ist. - DE - EASL 2016, Barcelona, 13.-17.4.2016 